\title{
Analysis of changes in hydrological cycle of a pristine mountain catchment. 2. Isotopic data, trend and attribution analyses
}

\author{
Ladislav Holko*, Michal Danko, Patrik Sleziak \\ Institute of Hydrology of the Slovak Academy of Sciences, Dúbravská cesta 9, 84104 Bratislava, Slovakia. \\ * Corresponding author. E-mail: holko@uh.savba.sk
}

\begin{abstract}
O}$ in precipitation at station Liptovský Mikuláš (about $8.5 \mathrm{~km}$ south from the outlet of the Jalovecký Creek catchment) remains constantly higher since 2014 that might be related to greater evaporation in the region of origin of the air masses bringing precipitation to the studied part of central Europe. Increased $\delta^{18} \mathrm{O}$ values are reflected also in the Jalovecký Creek catchment runoff. Seasonality of $\delta^{18} \mathrm{O}$ in the Jalovecký Creek became less pronounced since 2014. The most significant trends found in annual hydrological data series from the catchment in the study period 1989-2018 have the correlation coefficients 0.4 to 0.7 . These trends are found in the number of flow reversals (change from increasing to decreasing discharge and vice versa), June low flow, number of simple runoff events in summer months (June to September) and the flashiness index. The attribution analysis suggests that drivers responsible for the changes in these data series include the number of periods with precipitation six and more days long, total precipitation amount in February to June, number of days with precipitation in June to September and total precipitation in May on days with daily totals 10 $\mathrm{mm}$ and more, respectively. The coefficients of determination show that linear regressions between the drivers and supposedly changed data series explain only about $31 \%$ to $36 \%$ of the variability. Most of the change points detected in the time series by the Wild Binary Segmentation method occur in the second and third decades of the study period. Both hydrometric and isotopic data indicate that hydrological cycle in the catchment after 2014 became different than before.
\end{abstract}

Keywords: Oxygen isotope in precipitation and runoff; Time series; Trends and break points.

\section{INTRODUCTION}

Stable isotopes of oxygen and hydrogen in water are commonly used as tracers in climatology, hydrology and ecohydrology to determine sources of water, investigate the runoff formation and mean transit times of water in catchments (e.g., Clark and Fritz, 1997; Gat, 1996; Kendall and McDonnell, 1998). The long-term data on isotopic composition of precipitation and runoff can be helpful in identification of climatic variability. Rozanski et al. (1992) concluded that long-term changes in isotopic composition of precipitation over mid- and highlatitudes closely followed the long-term changes of surface air temperature. They also noted that isotopic composition of precipitation in mountain regions seemed to be more sensitive to the long-term air temperature fluctuations than in the lowaltitude regions. Kendall and Coplen (2001) showed that isotopic composition of modern precipitation is well reflected in the rivers and that the isotopic composition of the rivers represents the best available dataset on spatial distribution of stable isotopes in precipitation. Rank et al. (2014) reported significant changes in stable isotopic composition of the Danube River in Vienna on a decadal scale and attributed the remarkable increase in $\delta^{18} \mathrm{O}$ in the 1980 's mainly to temperature rising. Panarello and Dapeña (2009) used 10 years of monthly data on the isotopic composition of the Paraná River to conclude that the isotopic composition of the river is defined by the large-scale meteorological phenomena ENSO and ITCZ.

Concentration of heavy isotopes in water vapour above the oceans depends primarily on the air temperature. Increasing global temperature should therefore be reflected in an increased concentration of heavy isotopes in water vapour above the oceans caused by greater evaporation. The isotopic composition of precipitation on the continents differs from that of water vapour above the oceans. However, conditions at the source regions of vapour are among the main factors controlling the isotopic composition of precipitation over the mid- and highlatitudes (Rozanski et al., 1992). Therefore, we hypothetise that greater concentrations of heavy isotopes in the original vapour should be reflected also in continental precipitation and the long term data on the isotopic composition of precipitation and runoff could be used to detect the change in evaporation from the oceans.

Despite an obvious link between the isotopic composition of precipitation and local air temperature, the correlation is often not very strong. Stumpp et al. (2014) found an increase in oxygen 18 concentrations only at 20 out of 28 stations in Germany while the air temperature increased at almost all stations. They concluded that changes in isotopic composition of precipitation are influenced also by local factors which need to be further investigated. Pirk (2015) and Reckerth et al. (2017) presented the evaluation of the long-term data (12 or 26 years) on isotopic composition of rivers representing nine large catchments in Germany. They confirmed that isotopic composition of rivers can serve as a proxy for precipitation and that it can be an indicator for hydrological processes even in large basins.

Exploratory analysis of hydrometric and isotopic data identifies the data series showing trends or sudden changes that deserve additional examination. Merz et al. (2012) highlighted the need of going beyond the identification of change and focus on the search of the drivers by the attribution analysis. They conclude that in the studies analysing flood trends, the attribution statements are mostly based on qualitative reasoning or even speculations. Blöschl et al. (2019) stressed regional patterns of European floods that are attributed to different drivers - increasing autumn and winter rainfall in the northwestern Europe; decreasing precipitation and increasing evaporation in southern 
Europe, and decreasing snow cover and snowmelt, resulting from warmer temperatures, in eastern Europe. Stone et al. (2013) state that the key problems in detection and attribution of climate change impacts comprise limited availability of longterm observations, limited knowledge on processes and mechanisms involved in changing environmental systems, and widely different concepts applied in the scientific literature. This statement is in our opinion not valid only for the climate change impact studies, but also for the studies that "only" attempt to explain the drivers of variability found in the time series of hydrological data.

This study analyses multivariate time series of data from a small mountain catchment of the Jaloveký Creek (including the time series presented in the companion article Holko et al. 2020 , this issue) with the aim to detect trends or changes in behaviour over the study period 1989-2018 and attempt to find the drivers of suggested changes. We first present the time series of isotopic data in precipitation and catchment runoff (oxygen 18). Then, the trends and change points in selected data series are determined and the attribution analysis is conducted. The study differs from similar studies in that the analysis involves many different data series and the hydrological cycle of the studied research catchment is relatively well understood.

\section{DATA}

Data on isotopes of oxygen and hydrogen in water samples $\left(\delta^{18} \mathrm{O}, \delta^{2} \mathrm{H}\right)$ are collected in the Jalovecký Creek catchment since the 1990'. Isotopic composition of monthly precipitation (station Liptovský Mikuláš, elevation 570 m a.s.l.) is monitored since November 1990. Samples for the analysis of isotopic composition of the Jalovecký Creek have been collected at catchment outlet (elevation $820 \mathrm{~m}$ a.s.l.) with varying time steps (monthly, weekly, daily, sub-daily) between November 1991 and October 1993, in years 1988-2002 and since the year 2004. The variability of these two data sets in hydrological years 1991-2018 is examined here (see the companion article Holko et al. 2020, this volume, for the catchment and network descriptions).

Isotopic analysis of the samples was carried out by mass spectrometers (before 2011) and laser analyzers (since 2011) in Austria, Slovakia, Germany, Switzerland and in the Czech Republic. All precipitation samples were analysed for both oxygen and deuterium. Deuterium data on the stream samples are not available for the entire study period. An overall analytical accuracy of $\delta^{18} \mathrm{O}$ and $\delta^{2} \mathrm{H}$ (VSMOW) measurements is better than $0.2 \%$ and $1 \%$, respectively.

The exploratory analysis of the water balance and snow data series in the companion article (Holko et al., 2020, this volume) indicated several data series that exhibit the greatest (although not very pronounced) trends or abrupt changes which are statistically examined in this study.

\section{METHODOLOGY}

\section{Isotopic composition of water $\left(\delta^{18} \mathrm{O}, \delta^{2} \mathrm{H}\right)$}

The long-term variability in isotopic composition of precipitation and runoff based on monthly data is explored first. Because the ranges of monthly values in individual years are similar, raw monthly data could not indicate the longer-term variability. Therefore, the 12-months moving averages are calculated to remove the influence of seasonality (Rozanski et al., 1992) and the variability in isotopic composition of precipitation $\left(\delta^{18} \mathrm{O}, \delta^{2} \mathrm{H}\right.$, deuterium excess $\left.d=\delta^{2} \mathrm{H}-8 \delta^{18} \mathrm{O}\right)$ and air temperature in Liptovský Mikuláš is compared. The variability in moving averages of $\delta^{18} \mathrm{O}$ in catchment runoff is explored as well, although the data do not cover the entire period 19912018.

We further examine the variability in annual values of the isotopic composition of precipitation and runoff. Volume weighted mean annual values of $\delta^{18} \mathrm{O}$ in precipitation in Liptovský Mikuláš in hydrological years 1991-2018 are calculated and compared with the values observed at the two nearest stations having the long-term data on isotopic composition of precipitation in Krakow and Vienna (IAEA/WMO, 2019). The annual weighted mean values are calculated according to the following formula (written for the $\delta^{18} \mathrm{O}$ ):

$$
\delta^{18} O_{\text {annual }}=\frac{\sum_{i=1}^{12} P_{i} \delta^{18} O_{i}}{\sum_{i=1}^{n} P_{i}}
$$

where $P$ is monthly precipitation amount [mm] $i$ is month (November to October).

If the number of missing data (months) in a particular year is greater than two, the annual weighted mean is not calculated. Months with precipitation, having the deuterium excess less than 3 are excluded from calculations.

Annual volume weighted values of $\delta^{18} \mathrm{O}$ in precipitation and runoff are compared as well. The annual volume weighted values of $\delta^{18} \mathrm{O}$ in runoff are available for 18 years.

The stream water samples provide also an information on the isotopic composition of groundwater which is represented by samples collected in winter months, during the annual minimum flow period (usually from January to early March). Since the mean transit time of streamflow in the catchment is about one year (Dóša et al., 2011; Holko and Kostka, 2006), these values represent the combined contribution of rainfall and snowmelt from the previous year (mainly) to catchment storage. Stream water samples with the smallest concentration of heavy isotopes during the spring period indicate the contribution of the snowmelt to catchment runoff. Both characteristics, i.e the $\delta^{18} \mathrm{O}$ values representing the groundwater and the greatest snowmelt contribution, are presented, although due to shorter time series they are not used in the estimation of trends or abrupt changes.

\section{Trends and change points in the annual data series}

Our exploratory data analysis involves various types of data related to several components of the hydrological cycle, i.e., the water balance, runoff response and global evaporation and contribution of snowmelt to catchment runoff inferred from the oxygen isotope. It identifies the data series that appear to exhibit trends or changes in behaviour, either in magnitude or in variability. Trends and change points detection are calculated for these time series using the Mann-Kendall test and the Wild Binary Segmentation (WBS) method (Fryzlewicz, 2014), respectively. The two approaches are among the most common methods used in the time series analyses (e.g., Sharma et al., 2016; Yue et al., 2012). The Mann-Kendall test is a nonparametric test that analyses data for the increasing or decreasing (monotonic) trends. The test does not gain any information on the type (gradual or abrupt) or timing of the change (Chiverton et al., 2015). The WBS method is a relatively new method that has been shown to identify the change points correctly and that is computationally not very demanding. However, Sharma 
et al. (2016) showed that the method (like other methods they tested) failed to detect the change point location for the change in variance only.

Merz et al. (2012) proposed a framework for hypothesis testing in attribution analyses comprising the evidence of consistency, evidence of inconsistency and provision of confidence levels. According to this framework, the evidence of consistency should show that the detected change is consistent with the assumed drivers of change. The evidence of inconsistency should show that changes in other possible drivers are inconsistent with the change in the studied characteristic. Finally, the provision of confidence levels should quantify the strength of the attribution statement in terms of a likelihood statement. We apply this approach in the search of drivers that might be responsible for the changes detected in our data series. Selected data series in which a trend or change are indicated and correlation coefficients of linear regression with time exceed the value of 0.4 , are compared to the data series of possible drivers represented by precipitation characteristics. The correlation between the two data series (the data series with an identified change and the driver data series) is evaluated by Pearson correlation coefficient at significance level 0.05 .

\section{RESULTS}

\section{Isotopic composition of water}

Moving averages of monthly air temperature and isotopic composition of precipitation (Fig. 1) in Liptovský Mikuláš do not indicate a trend over hydrological years 1989-2018. Compared to the long-term average, a longer period of isotopically depleted precipitation was observed approximately between
December 2002 and December 2006 that corresponds to lower air temperatures. A longer period of isotopically enriched precipitation occured approximately between January 2014 and December 2017. Isotopic enrichment of precipitation in that period is slightly shifted in time compared to the air temperature increase (Fig. 1). Similarity of the isotopic composition of precipitation and local air temperature over the entire period 1991-2018 is obvious, but the correlation is not very good (the correlation coefifcient of linear regression between $\delta^{18} \mathrm{O}$ in precipitation and air temperature is 0.523 ).

Although the data on isotopic composition of runoff do not cover the entire period 1991-2018, it is obvious that the values since 2014 are less variable and higher than in period 20052013 (Fig. 1, Fig. 2). These higher values correspond to the period of isotopically enriched precipitation mentioned above.

Seasonality in isotopic composition of catchment runoff since 2014 is less pronounced than before, except the significant spring depletion in 2018 (Fig. 2). It could be related to a change in temporal evolution of snow accumulation and melt during winter seasons.

Higher concentrations of heavy isotopes in precipitation in Liptovský Mikulás since 2014 are even better visible in the annual volume weighted data (Fig. 3). Similar behaviour seems to be observed also at the nearest neighbouring stations in Krakow and Vienna although the data from hydrological years 2017 and 2018 are not available. Higher concentrations of heavy isotopes in precipitation in the last years of the study period are reflected also in catchment runoff. We note that isotopic composition of precipitation in Liptovký Mikuláš (570 $\mathrm{m}$ a.s.1.) shown in Figs. 1 and 3 does not represent the isotopic composition of water feeding the Jalovecký Creek catchment

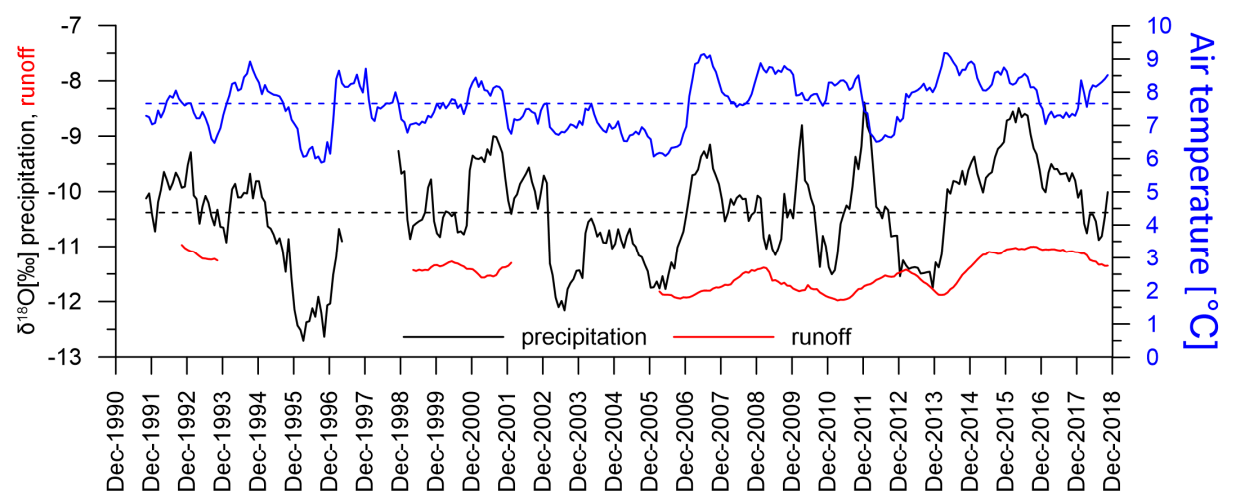

Fig. 1. Moving average of monthly $\delta^{18} \mathrm{O}$ in precipitation in Liptovský Mikuláš (the black line), air temperature in Liptovský Mikuláš (the blue line) and $\delta^{18} \mathrm{O}$ in the Jalovecký Creek catchment runoff (the red line) in hydrological years 1991-2018; the dotted lines indicate the long-term averages of air temperature (blue) and $\delta^{18} \mathrm{O}$ in precipitation (black); note that elevation of station Liptovský Mikulás is $570 \mathrm{~m}$ a.s.l. while the mean elevation of the Jaloveký Creek catchment is $1500 \mathrm{~m}$ a.s.l.

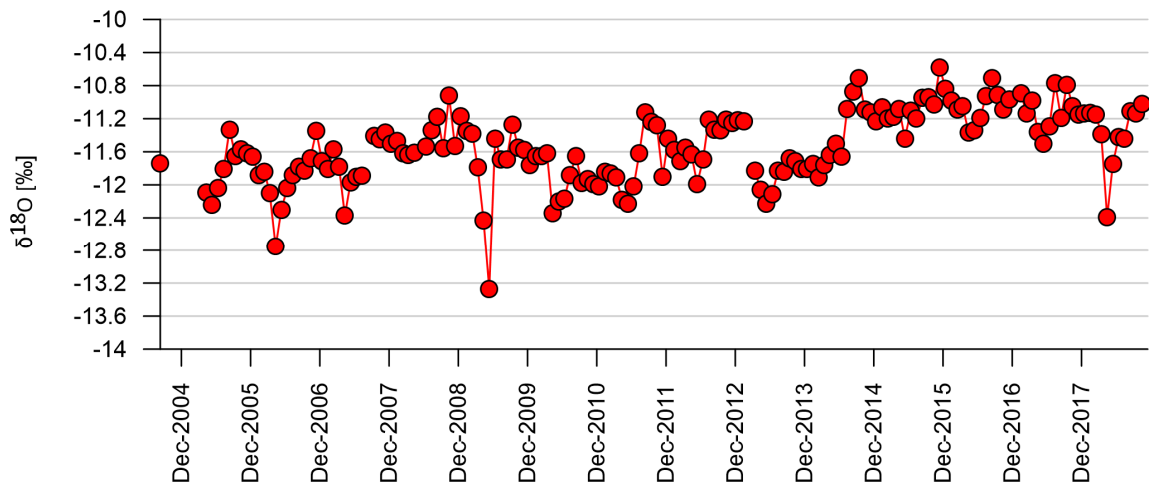

Fig. 2. Monthly weighted $\delta^{18} \mathrm{O}$ in the Jalovecký Creek at catchment outlet in period August 2004-October 2018. 
that has much higher elevation (820-2178 m a.s.l., mean 1500 $\mathrm{m}$ a.s.l.) and thus receives isotopically lighter precipitation.

Isotopic composition of the Jalovecký Creek during winter low flow period that represents catchment groundwater, is shown in Fig. 4. Although the data series does not fully cover the entire study period, the interannual variability of the groundwater $\delta^{18} \mathrm{O}$ is approximately $0.5 \%$ with greater values measured until 2002 followed by smaller values in the years 2005-2014. The greater values since 2015 correspond to the pattern of isotopic composition of precipitation. The interannual variability of $\delta^{18} \mathrm{O}$ in the stream water during the time of maximum spring discharge that represents the greatest influence of the snowmelt is almost $2 \%$. This variability does not correlate well with the simulated catchment snow characteristics (SWE, accumulated SWE). The difference between the isotopic composition of groundwater (as defined above) and the isotopic composition of the stream water during the snowmelt period could be interpreted as a qualitative measure of the snowmelt contribution to catchment runoff. Fig. 4 shows a negligible difference in spring 2014 and indicates a smaller influence of the snowmelt water in years 2015-2017 compared to most of the previous years (as suggested also above by Fig. 2). However, the influence of snowmelt in spring 2018 is greater again.

\section{Trends and change points in the annual data series}

Summary information on the results of trend and change point analyses is given in Table 1 . The table lists the time series (denoted as Indicators) in which the exploratory analysis indicates the most pronounced trends or changes in behaviour over the study period 1989-2018. For the convenience they are divided into data related to water balance, hydrological response, storage and other. Some of them are plotted in Fig. 5 that shows that the only time series exhibiting a clear monotonic increasing trend is the number of flow reversals per year. Other data series contain abrupt changes in some part of the study period rather than monotonic trends (e.g. the annual runoff coefficients or June low flow). As written above, the Mann-Kendall test (MK in Table 1) does not provide an information on the type of change. Therefore, the years indicated by the WBS method as change points (abrupt changes in the time series) are given in Table 1 and Fig. 5 as well.
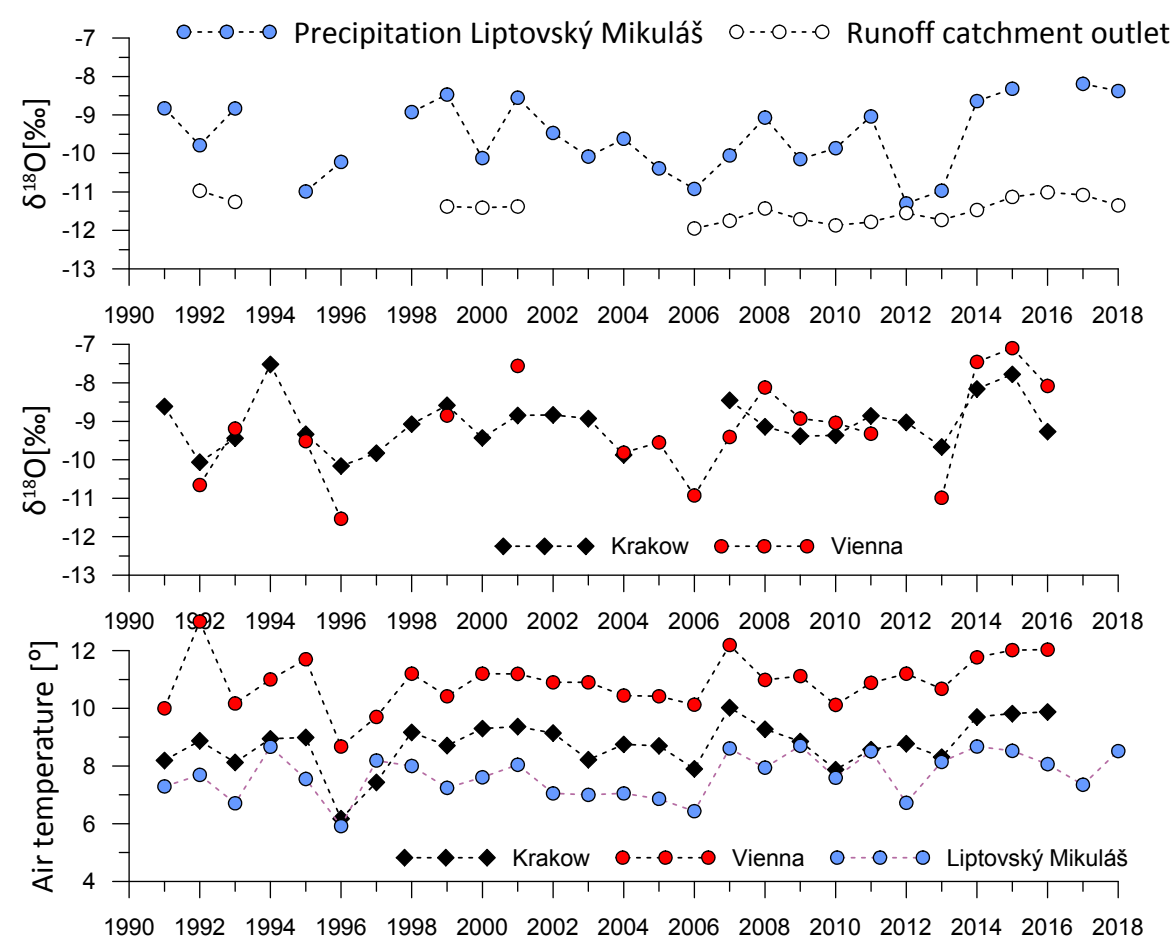

Fig. 3. Annual volume weighted values of $\delta^{18} \mathrm{O}$ in precipitation in Liptovský Mikuláš, Krakow and Vienna and in the Jalovecký Creek at the outlet of the catchment (the top and middle panels) and mean annual air temperatures in hydrological years 1991-2018 (the bottom panel).

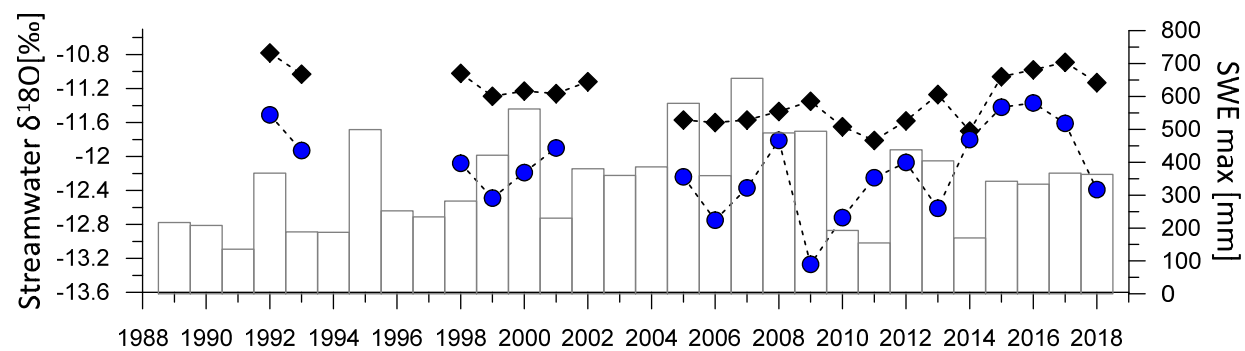

1988199019921994199619982000200220042006200820102012201420162018

Fig. 4. $\delta^{18} \mathrm{O}$ in the Jalovecký Creek during winter low flow conditions and during the greatest $\delta^{18} \mathrm{O}$ depletion caused by the snowmelt and simulated maximum SWE in the catchment. 


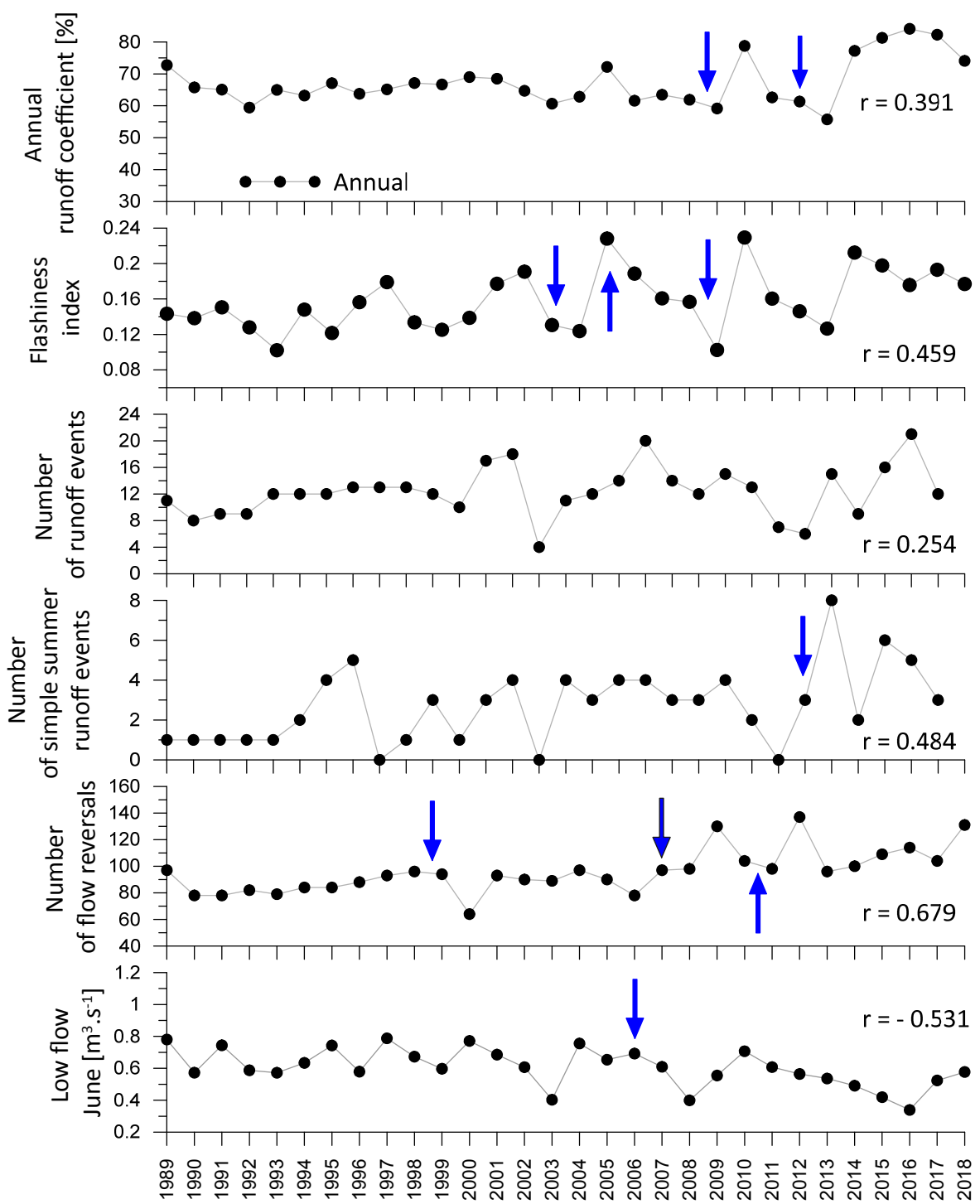

Fig. 5. The time series of annual data in which the exploratory data and statistics (trends and change points determination) indicated pronounced changes; $r$ is the correlation coefficient of the linear trend over the study period (linear regression of annual values of indicators against time); the arrows indicate change points determined by the WBS method; if the arrows point between the years, both years were identified by WBS as the change points.

Table 1 shows that the greatest correlation coefficients (i.e. mathematically the closest relationships of an indicator with time) are obtained for:

- number of flow reversals

- low flow in June

- number of simple summer events and

- flashiness index.

We have attempted to find drivers of changes for these four time series by an attribution analysis described in Methodology (i.e., find the possible driver, examine the consistency, confirm the inconsistency with other potential drivers and examine the statistical significance). All time series seem to be dominantly related to precipitation regime (the relationships with air temperature were poor). Therefore, the attribution focused on finding characteristics of catchment precipitation that correlate best with the above data series. Tested precipitation characteristics include precipitation amounts for different time steps (annual, seasonal, monthly) and thresholds (e.g., total precipitation for days with more than $10 \mathrm{~mm}$ per day), number of days with precipitation and number of wet and dry periods of different duration (from 1 to more than 10 successive days with/without precipitation).
Change in the number of flow reversals was attributed to the change in the number of wet periods with six and more successive days with precipitation per year. Linear regression between the two data series (wet periods as an independent variable and number of flow reversals as a dependent variable) has coefficient of determination $\mathrm{R}^{2}=0.353$ (Fig. 6) and the correlation is statistically significant at level 0.05 . The total number of days with precipitation per year was rejected as a possible driver because the correlation is worse $\left(\mathrm{R}^{2}=0.275\right)$ and it is not statistically significant.

Low flow in June is the only of the four data series in the attribution analysis that might not be affected only by precipitation characteristics, but also by possible changes in the snow accumulation and melt. However, the best correlation and statistically significant Pearson correlation coefficient (i.e., the driver of the change) were found only for the total precipitation amount in February to June (Fig. 6). Coefficient of determination obtained by linear regression of the two data series was 0.343 . Analysis of monthly air temperature as another possible driver does not indicate pronounced changes during the snow accumulation and melt periods and the air temperature was thus rejected as the driver of the June low flow change. 
Table 1. Time series in which the exploratory analysis indicated the most pronounced changes during the study period; significance of the monotonic trend was tested by the Mann-Kendall test (MK trend) at significance level 0.05 (YES if the trend is significant); identification of change points employed the WBS method; "-“" means that a significant trend or change point were not found.

\begin{tabular}{|c|c|c|c|c|c|}
\hline Data type & $\begin{array}{l}\text { Indicator (time series } \\
\text { examined) }\end{array}$ & $\begin{array}{l}\text { Obtained from, } \\
\text { time step }\end{array}$ & $\begin{array}{c}\text { Correlation } \\
\text { coefficient (linear regression } \\
\text { of an indicator versus time) }\end{array}$ & $\begin{array}{l}\mathrm{MK} \\
\text { trend }\end{array}$ & Change point \\
\hline $\begin{array}{l}\text { Water } \\
\text { balance }\end{array}$ & Runoff coefficient & $\begin{array}{l}\text { precipitation and } \\
\text { runoff, annual }\end{array}$ & 0.391 & - & $\begin{array}{c}2008,2009, \\
2012 \\
\end{array}$ \\
\hline \multirow[t]{7}{*}{$\begin{array}{l}\text { Runoff } \\
\text { response }\end{array}$} & Rise rate & discharge, daily & -0.448 & Yes & - \\
\hline & Number of events per year & discharge, hourly & 0.254 & Yes & $\begin{array}{c}1999,2001, \\
2002,2010,2014 \\
\end{array}$ \\
\hline & Annual maximum & discharge, hourly & 0.306 & - & $1994,2012,2013,2015$ \\
\hline & Fall rate & discharge, daily & 0.316 & Yes & - \\
\hline & Flashiness index & discharge, daily & 0.459 & Yes & $2003,2005,2008,2009$ \\
\hline & No. of simple summer events & discharge, hourly & 0.484 & Yes & 2012 \\
\hline & No. of flow reversals & discharge, daily & 0.679 & Yes & $1998,1999,2007,2010,2011$ \\
\hline \multirow[t]{2}{*}{ Storage } & June low flow & discharge, daily & -0.531 & Yes & 2006 \\
\hline & June flow & discharge, daily & -0.366 & Yes & 2005 \\
\hline
\end{tabular}
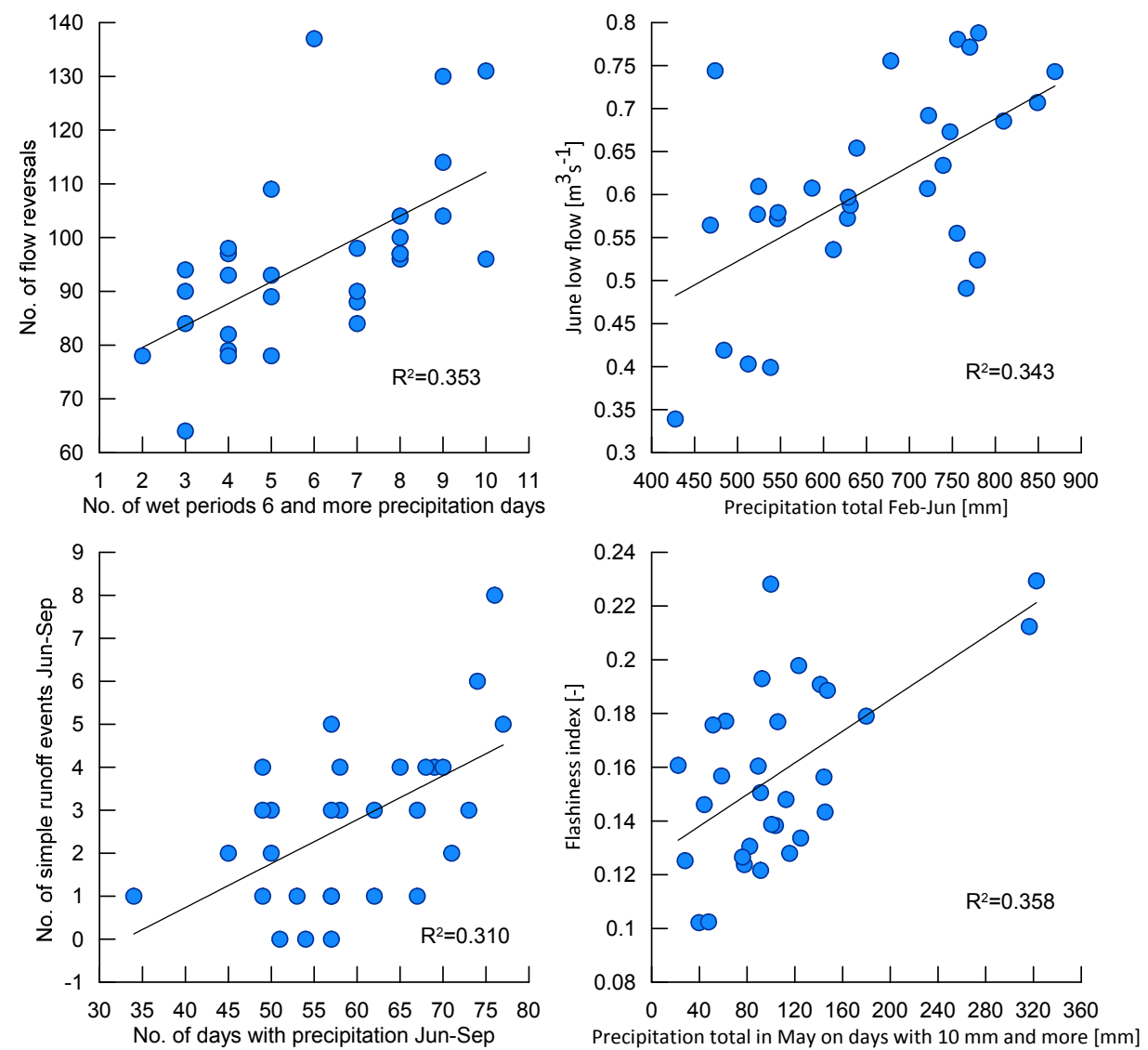

Fig. 6. Correlations between the drivers (plotted on the horizontal axes) and changed time series (vertical axes) found in the attribution analysis for the time series that exhibited the greatest changes over the study period (see also Fig. 5).

The change in the number of simple runoff events in summer seasons (June to September) is best correlated $\left(\mathrm{R}^{2}=0.310\right)$ with the number of days with precipitation in the same period (Fig. 6). Precipitation amount or number of days with precipitation above certain thresholds were rejected as possible drivers due to much worse and statistically insignificant correlations.

Flashiness index reflects the magnitude of changes in discharge of the successive days standardized by the total discharge over the studied period (hydrological year in this study). The analysis of monthly flashiness indices revealed that the greatest trends over the study period (1989-2018) occurred in November, April and May. Therefore, the attribution of changes in annual flashiness index focused on spring months. Sum of precipitation in May on days with precipitation amount $10 \mathrm{~mm}$ and more is identified as the driver. The correlation between this driver and the flashiness index is statistically significant and coefficient of determination is 0.358 (Fig. 6). Number of days with precipitation in the entire hydrological year, in individual months or in a combination of several months as well as precipitation amounts were rejected as possible drivers. 


\section{DISCUSSION}

We are not aware of other studies analysing similar multivariate data series from small mountain catchments. Therefore, instead of comparing our results with the results of other studies, we focus on some thoughts on the uncertainties that might be related to our analyses and additional data series or approaches that might be useful in similar studies.

Higher concentrations of heavy isotopes in precipitation (both oxygen and hydrogen) in the last years of the study period might reflect increased global evaporation. Similarity with data from Krakow and Vienna suggests that the pattern observed in Liptovský Mikulás is not caused by local drivers. Although Figs. 1 and 3 confirm the links between the local air temperatures and isotopic composition of precipitation, the correlations over the entire period (1991-2018) are not very strong at any of the three stations. This is a known fact that has already been mentioned in other studies (e.g. Rozanski et al., 1993; Stumpp et al., 2014). Yet, our data show that an increase of the air temperature since 2013 corresponds to that of $\delta^{18} \mathrm{O}$ in precipitation. Global data sets (e.g., https://data.giss.nasa.gov/gistemp/) indicate an unprecedented increase in air temperature in northern hemisphere or in northern Atlantic (the main source of precipitation for the study area) since 2014 that might result in greater evaporation. Although the analysis comprising global data (both climatic and isotopic) is beyond the scope of this study, it would be an interesting topic of further research.

Quantification of snowmelt contribution to catchment runoff or groundwater recharge from winter and summer precipitation using stable isotopes (e.g., Jasechko et al., 2014; Šanda et al., 2019) are other approaches that could point at changes in hydrological cycle of catchments. However, previous studies in the Jalovecký Creek catchment showed that isotopic composition of the snowmelt water is rather different from that of winter precipitation and has a significant spatial variability (Holko, 1995; Holko et al., 2013). Thus, the results of calculations based on the two-component mixing model (Jasechko et al., 2014; Šanda et al., 2019) would be very uncertain in the study catchment in which the detailed data on isotopic composition of the snowmelt water which is not available for the entire study period. Comparison of the isotopic composition of stream during periods when the runoff is fed from the groundwater storage with periods of maximum annual isotopic depletion (the spring snowmelt and in some years perhaps also the isotopically lighter spring precipitation) therefore only qualitatively indicates smaller contribution of snowmelt water between 2011 and 2017. However, this smaller snowmelt water contribution agrees with the change in snow accumulation and melting suggested by the less pronounced seasonal variability of the isotopic composition of the Jalovecký creek shown in Fig. 2.

Change points identified with the help of statistics (the WBS method) do not clearly show one well defined period for all or majority of studied data series. However, apart from two exceptions, all identified change points occur in the second and third decades of the study period (Table 1).

We would like to stress that the objective of this study is not to look for evidences of climate change. The 30 years long data series are not long enough to examine the effects of climate change (Kundzewicz and Robson, 2004). Furthermore, data from the Kasprowy Wierch and Skalnaté Pleso stations show that the air temperature, precipitation and snow cover did not significantly change during the study period and that the study period is already warmer than previous decades. The objective of this study is to examine if and which changes can be identified in relatively long data series characterizing the hydrologi- cal cycle of a small mountain catchment that has been little affected by direct human activities and relatively well studied.

The results show that despite a number of experiments conducted in the catchment which provided some unique data, examination of the changes in catchment hydrological cycle has to rely on the standard data sets of precipitation, air temperature, and runoff. Precipitation does not appear to exhibit changes at the time scales studied and evapotranspiration cannot be measured at catchment scale. Thus, runoff remains the only water balance component that can be analysed more carefully. Chiverton et al. (2015) proposed an approach based on variograms that might be useful in our future analyses.

Regular snow cover measurements at snow courses located at different elevations are perhaps the only data series, available in our catchment that are not commonly measured in similar catchments on the long-term basis. Because such measurements cannot be conducted very frequently and in a very dense network, some important snow cover characteristics such as dates of its beginning and end that could indicate the long-term changes, cannot be evaluated from measured snow course data on a catchment scale. The only reasonable approach to obtain the catchment-scale snow characteristics in mountain catchments of a similar size (too big for the detailed measurements, too small for the remotely sensed data that would cover the entire study period) is mathematical modelling. Because of uncertainties that are always present in modelling, we do not evaluate duration of snow cover in individual winters. Simulated SWE is only used to supplement the information on SWE maxima obtained from measured data and provide an information on total accumulation of snow in the catchment that we believe is less sensitive to modelling uncertainties.

Our effort in focusing on catchment scale rather than on point data (we do not analyse air temperature data from the stations for example) also leads to the uncertainty related to extrapolation of the point precipitation and air temperature data.

Merz et al. (2012) noted that in most flood time series analyses studies, very little effort is devoted to attribution of the trends and change points to the drivers that caused them. The same applies to other studies analysing hydrological and meteorological time series data. While the detection of changes is an important component of the time series analysis, in our opinion the only effort possibly leading to a progress in understanding of hydrological cycle is the search for the drivers of the changes. We have attempted to search for the drivers responsible for the changes in our data series suggested by the exploratory analysis. Because the air temperature and snow accumulation are poorly correlated with the data series in interest, our search for the drivers was limited to precipitation characteristics with not better than daily temporal resolution. It is possible that some changes (e.g., greater runoff coefficients) are also related to the change of the short-time precipitation characteristics (e.g., rainfall intensity), which are not available in the study catchment for the entire study period. Fig. 6 shows that regressions obtained in the attribution analysis are not very strong. Other possible drivers describing for example the wetness or storage states of the catchment are not available. Naturally, it is also possible that there are other drivers we are not aware of or the influence of which is currently not well understood (e.g. changing forest structure). Useful thoughts about the uncertainties in our ability to understand the drivers and predict future behaviour are given by Taleb (2007).

Some relationships obtained by the attribution analysis suggest new directions in the research of hydrological response of our catchment, e.g., of the role of short and long term wet periods or number of days with precipitation rather than precipita- 
tion totals or thresholds. Evaluation of additional isotopic data (e.g. weekly samples of catchment runoff) could provide better understanding of the changes that probably occurred after 2014.

\section{CONCLUSIONS}

Isotopic data indicate greater concentrations of heavier isotopes in precipitation since 2014 and less pronounced seasonality in the isotopic composition of stream water. The attribution analysis related the most pronounced (although statistically weak) changes to characteristics of precipitation regime and indicated some interesting relationships that may be subject of future research.

The study shows the value of the long-term hydrological and isotopic monitoring in small mountain catchments. At the same time, it documents that despite better data and knowledge of the hydrological cycle in a research catchment compared to other, less-studied catchments, the attribution analysis is still uncertain due to the unavailability of data on possible drivers. While the time series analysis of longer hydrological data sets should remain part of routine data processing (to check for an unusual behaviour), the ability of hydrologists to explain the variability found in the hydrological time series is in our opinion still rather limited due to an inadequate understanding of the hydrological cycle.

Acknowledgements. This study was supported by grants from the Slovak Academy of Sciences VEGA (project No. 2/0065/19) and the Slovak Research and Development Agency (APVV) (project No. 15-0497). Data collection was supported by project ITMS 26210120009 Infrastructure completion of hydrological research stations, of the Research \& Development Operational Programme funded by the ERDF. The work of PS was supported by the Stefan Schwarz grant of the Slovak Academy of Sciences.

\section{REFERENCES}

Blöschl, G. et al., 2019. Changing climate both increases and decreases European river floods. Nature, 573, 108-111.

Chiverton, A., Hannaford, J., Holman, I.P., Corstanje, R., Prudhomme, C., Hess, T.M., Bloomfield, J.P., 2015. Using variograms to detect and attribute hydrological change. Hydrol. Earth Syst. Sci., 19, 2395-2408. DOI: 10.5194/hess19-2395-2015.

Clark, I.D., Fritz, P., 1997. Environmental Isotopes in Hydrogeology. CRC Press, New York., 352 p.

Dóša, M., Holko, L., Kostka, Z., 2011. Estimation of the mean transit times using isotopes and hydrograph recessions. Die Bodenkultur, 62, 1-4, 47-52.

Fryzlewicz, P., 2014. Wild binary segmentation for multiple change-point detection. The Annals of Statistics, 42, 6, 2243-2281.

Gat, J., 1996. Oxygen and hydrogen isotopes in the hydrologic cycle. Annu. Rev. Earth Planet. Sci., 24, 225-262.

Holko, L., 1995. Stable environmental isotopes of ${ }^{18} \mathrm{O}$ and ${ }^{2} \mathrm{H}$ in hydrological research of mountainous catchment. J. Hydrol. Hydromech., 43, 4-5, 249-274.

Holko, L., Kostka, Z., 2006. Hydrological research in a highmountain catchment of the Jalovecký Creek. J. Hydrol. Hydromech., 54, 2, 192-206. (In Slovak.)

Holko, L., Danko, M., Dóša, M., Kostka, Z., Šanda, M., Pfister L., Iffly, J.F., 2013. Spatial and temporal variability of stable water isotopes in snow related hydrological processes. Die Bodenkultur, 64, 3-4, 39-45.

Holko, L., Sleziak, P., Danko, M., Bičárová, S., Pociask-
Karteczka, J., 2020. Analysis of changes in hydrological cycle of a pristine mountain catchment: 1 . Hydrometric data. Journal of Hydrology and Hydromechanics, 68, 2, 180-191.

IAEA/WMO 2019. Global Network of Isotopes in Precipitation. The GNIP Database. Accessible at: https://nucleus.iaea.org/wiser, assessed in August 2019.

Jasechko, S., Birks, S.J., Gleeson, T., Wada, Y., Fawcett, P.J., Sharp, Z.D., McDonnell, J.J., Welker, J.M., 2014. The pronounced seasonality of global groundwater recharge. Water Resour. Res., 50, 8845-8867, DOI: 10.1002/2014WR015809.

Kendall, C., Coplen, T.B., 2001. Distribution of oxygen-18 and deuterium in river waters across the United States. Hydrol. Process., 15, 1363-1393.

Kendall, C., McDonnell, J.J. (Eds.), 1998. Isotope Tracers in Catchment Hydrology. Elsevier Science, 839 p.

Kundzewicz, Z.W., Robson, A., 2004. Change detection in hydrological records - a review of the methodology. Hydrological Sciences Journal, 49, 1, 7-19.

Merz, B., Vorogushyn, S., Uhlemann, S., Delgado, J., Hundecha, Y., 2012. HESS Opinions "More efforts and scientific rigour are needed to attribute trends in flood time series". Hydrol. Earth Syst. Sci., 16, 1379-1387. DOI: 10.5194/hess-16-1379-2012.

Panarello, H.O., Dapeña, C., 2009. Large scale meteorological phenomena, ENSO and ITCZ, define the Paraná River isotope composition. J. Hydrol., 365, 105-112.

Pirk, A., 2015. Long-term data set analysis of stable isotopic composition in German rivers. MSc Thesis, Albert-LudwigsUniversity Freiburg, 92 p.

Rank, D., Wyhlidal, S., Schott, K., Jung, M., Heiss, G., Tudor, M., 2014. A 50 years' isotope record of the danube river water and its relevance for hydrological, climatological and environmental research. Acta Zoologica Bulgarica 66, 109-115.

Reckerth, A., Stichler, W., Schmidt, A., Stumpp. C., 2017. Long-term data set analysis of stable isotopic composition in German rivers. J. Hydrol., 552, 718-731.

Rozanski, K., Araguás-Araguás, L., Gonfiantini, R., 1992. Relation between long-term trends of oxygen-18 isotope composition of precipitation and climate. Science, 258, 981-985.

Rozanski, K., Araguás-Araguás, L., Gonfiantini, R., 1993. Isotopic Patterns in Modern Global Precipitation. In: Climate Change in Continental Isotopic Records. Geophysical Monograph 78, $36 \mathrm{p}$.

Sharma, S., Swayne, D.W., Obimbo, C., 2016. Trend analysis and change point techniques: a survey. Energ. Ecol. Environ., 1, 3, 123-130. DOI: 10.1007/s40974-016-0011-1.

Stone, D., Auffhammer, M., Carey, M. et al., 2013. The challenge to detect and attribute effects of climate change on human and natural systems. Climatic Change, 121, 381. https://doi.org/10.1007/s10584-013-0873-6.

Stumpp, C., Klaus, J., Stichler, W., 2014. Analysis of long-term stable isotopic composition in German precipitation. J. Hydrol., 517, 351-361.

Šanda, M., Vitvar, T., Jankovec, J., 2019. Seasonal subsurface water contributions to baseflow in the mountainous Uhlírská catchment (Czech Republic). J. Hydrol. Hydromech., 67, 2019, 1, 41-48. DOI: 10.2478/johh-2018-0018.

Taleb, N.N., 2007. The Black Swan: The Impact of the Highly Improbable. Random House, ISBN 978-1400063512.

Yue, S., Kundzewicz, Z.W., Wang, L., 2012. Detection of changes. In: Kundzewicz, Z.W. (Ed.): Changes in Flood Risk in Europe. IAHS Press, Wallingford, UK, pp. 387-408.

Received 30 September 2019 Accepted 21 February 2020 